\title{
Erratum to: Numerical Simulation of Sub-Terahertz Thermal Emission: RADYN Code
}

\author{
A. S. Morgachev ${ }^{a, *}$, Yu. T. Tsap ${ }^{c}$, V. V. Smirnova ${ }^{c}$, G. G. Motorina ${ }^{b, d}$, and M. Bárta ${ }^{d}$ \\ ${ }^{a}$ Lobachevsky State University of Nizhny Novgorod, Nizhny Novgorod, Russia \\ ${ }^{b}$ Central Astronomical Observatory at Pulkovo of Russian Academy of Sciences, St. Petersburg, Russia \\ ${ }^{c}$ Crimean Astrophysical Observatory, Russian Academy of Sciences, Nauchny, Crimea, Russia \\ ${ }^{d}$ Astronomical Institute of the Czech Academy of Sciences, Ondřejov, Czech Republic \\ *e-mail:a.s.morgachev@mail.ru \\ Received May 11, 2021; revised May 11, 2021; accepted May 11, 2021
}

DOI: $10.1134 / \mathrm{S} 0016793221070288$

The affiliation of the author M. Bárta should read as follows:

${ }^{d}$ Astronomical Institute of the Czech Academy of Sciences, Ondřejov, Czech Republic

The original article can be found online at https://doi.org/10.1134/S0016793220080174 